Supporting Information to

\title{
Quiet Outer Membrane Protein G (OmpG) Nanopore for Biosensing
}

\author{
Raghavendar Reddy Sanganna Gari, Patrick Seelheim, Binyong Liang, and Lukas K. Tamm*
}

Department of Molecular Physiology and Biological Physics, Center for Cell and Membrane Physiology at the University of Virginia, Charlottesville, Virginia 22908, United States of America. 
Global Protein alignment. Reference molecule: OmpG, Region 1 to 301

Sequences: 2. Scoring matrix: BLOSUM 62

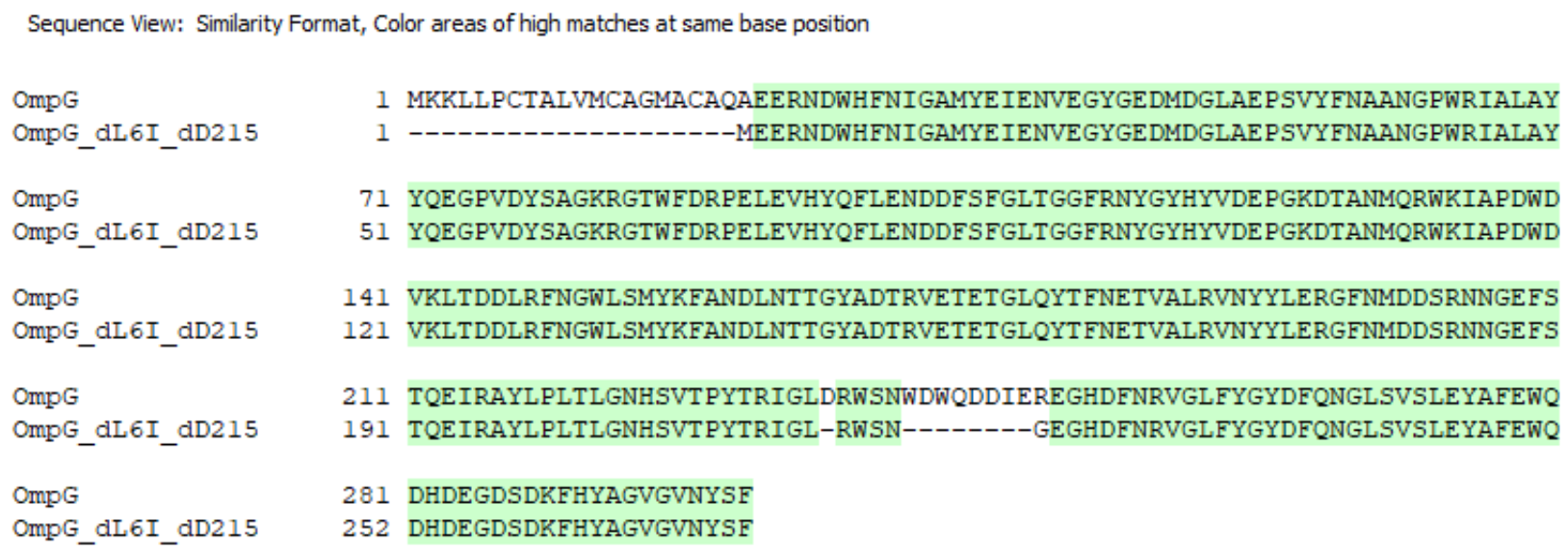

Supplementary Figure S1. Alignment of the OmpG reference sequence (UniProtKB accession no. $\mathrm{P} 76045)$ to the $\Delta \mathrm{L} 6-\Delta \mathrm{D} 215 \mathrm{OmpG}$ construct. The reference sequence contains the $\mathrm{N}$-terminal signal peptide (residues 1-21) that is cleaved off during maturation of OmpG. This peptide is replaced with a starting methionine in our construct. Residue 1 in our numbering scheme corresponds to E22 in the reference sequence.

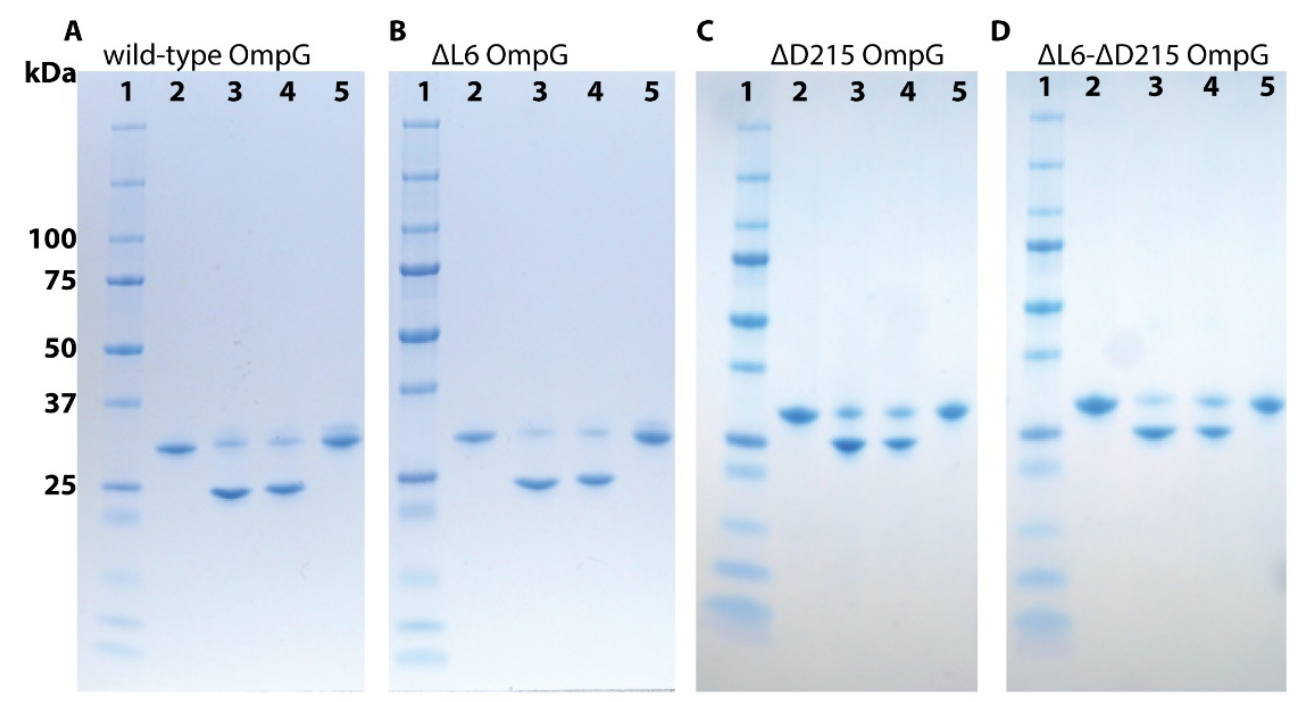

Supplementary Figure S2. Refolding of wild-type (A), $\Delta$ L6 (B), $\Delta$ D215 (C), $\Delta$ L6- $\Delta$ D215 (D) OmpG constructs. Lanes 1 to 5 are as follows: molecular weight markers (1), OmpG in $8 \mathrm{M}$ urea (2), OmpG in $70 \mathrm{mM} \beta-\mathrm{OG}$ (3), OmpG in $25 \mathrm{mM}$ DPC (4), and OmpG in $25 \mathrm{mM}$ DPC and subsequently boiled (5). 
A

$\mathrm{pH} 6.0$

$\mathrm{pH} 7.4$

$\mathrm{pH} 8.5$

$\Delta$ L6 OmpG
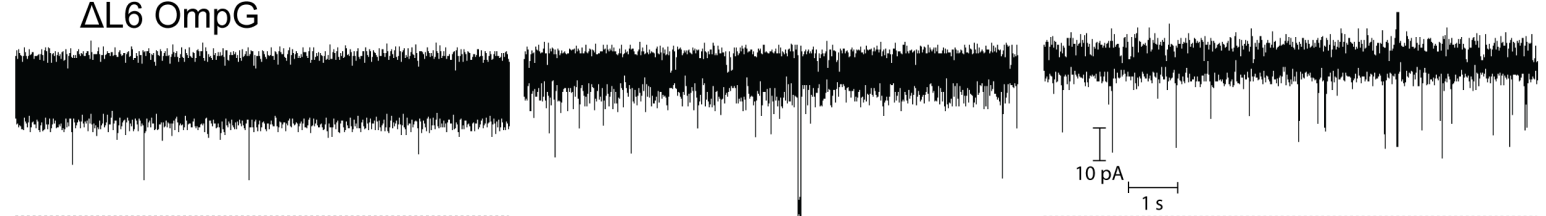

B

$\triangle \mathrm{D} 215 \mathrm{OmpG}$
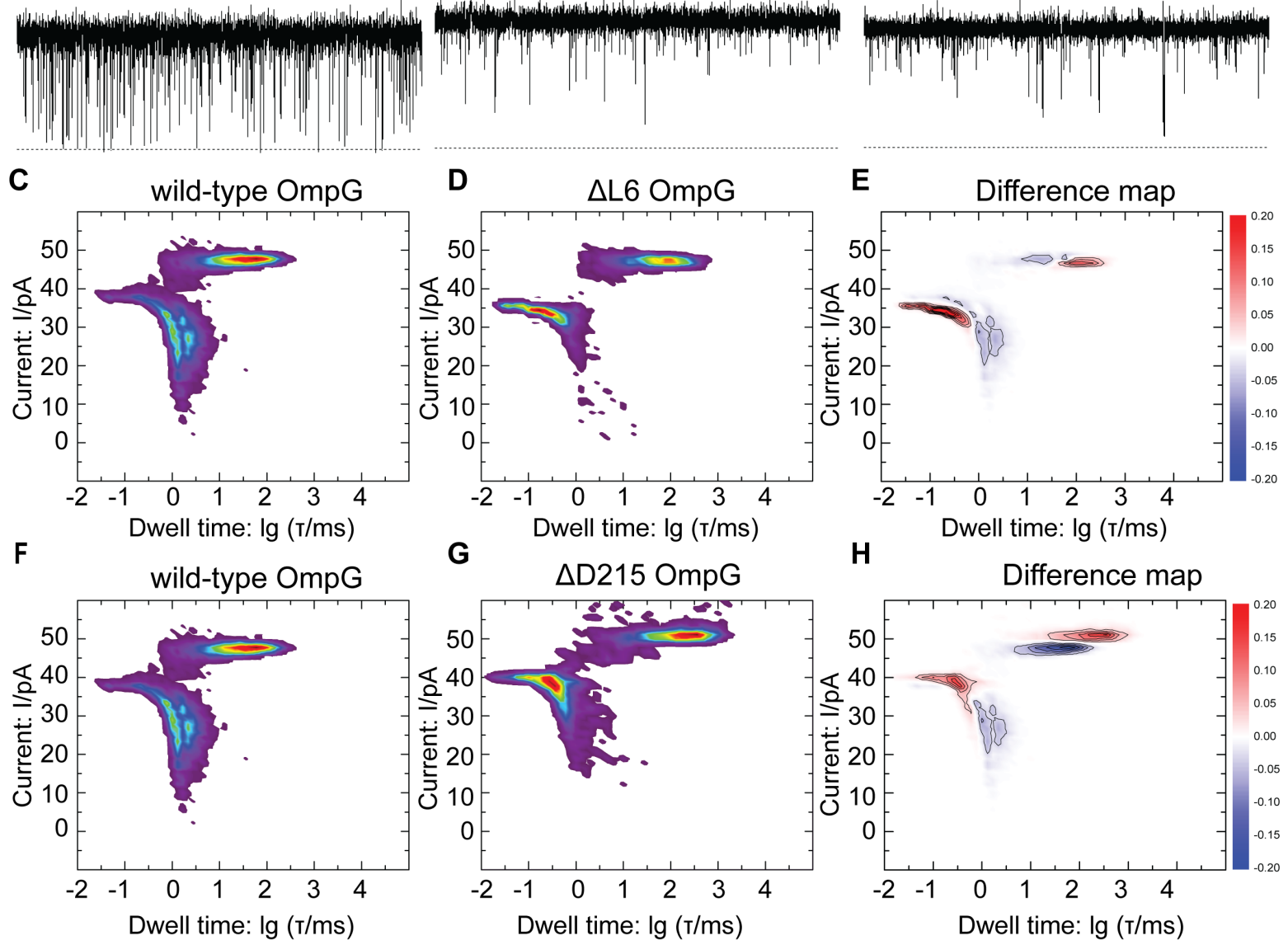

H

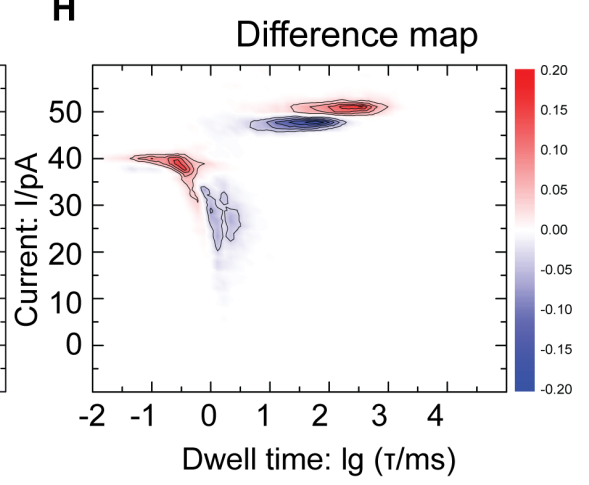

Supplementary Figure S3. Electrophysiological characteristics of $\Delta$ L6 and $\Delta$ D215 OmpG. A, $10 \mathrm{~s}$ segments from representative current traces at $-40 \mathrm{mV}$ of a single $\triangle \mathrm{L} 6 \mathrm{OmpG}$ in a solvent-free $\mathrm{DPhPC}$ black lipid membrane in $1 \mathrm{M} \mathrm{KCl}$ buffered at the indicated $\mathrm{pH}$ values. B, $10 \mathrm{~s}$ segments from representative current traces of a single $\Delta \mathrm{D} 215 \mathrm{OmpG}$ under same conditions as in A. C, D, F and $\mathbf{G}$, Probability density histograms of current versus dwell time distribution from at least 15 minutes of single channel recordings of wild-type (C and F), $\Delta \mathrm{L} 6(\mathrm{D})$, and $\Delta \mathrm{D} 215 \mathrm{OmpG}(\mathrm{G})$ at $\mathrm{pH}$ 7.4. E and $\mathbf{H}$, Difference maps of $\mathrm{D}-\mathrm{C}(\mathrm{E})$ and $\mathrm{G}-\mathrm{F}(\mathrm{H})$ to visualize changes in the current versus dwell time distributions between $\triangle \mathrm{L} 6$ and wild-type OmpG $(\mathrm{E})$ and between $\Delta \mathrm{D} 215$ and wild-type OmpG $(\mathrm{H})$. 

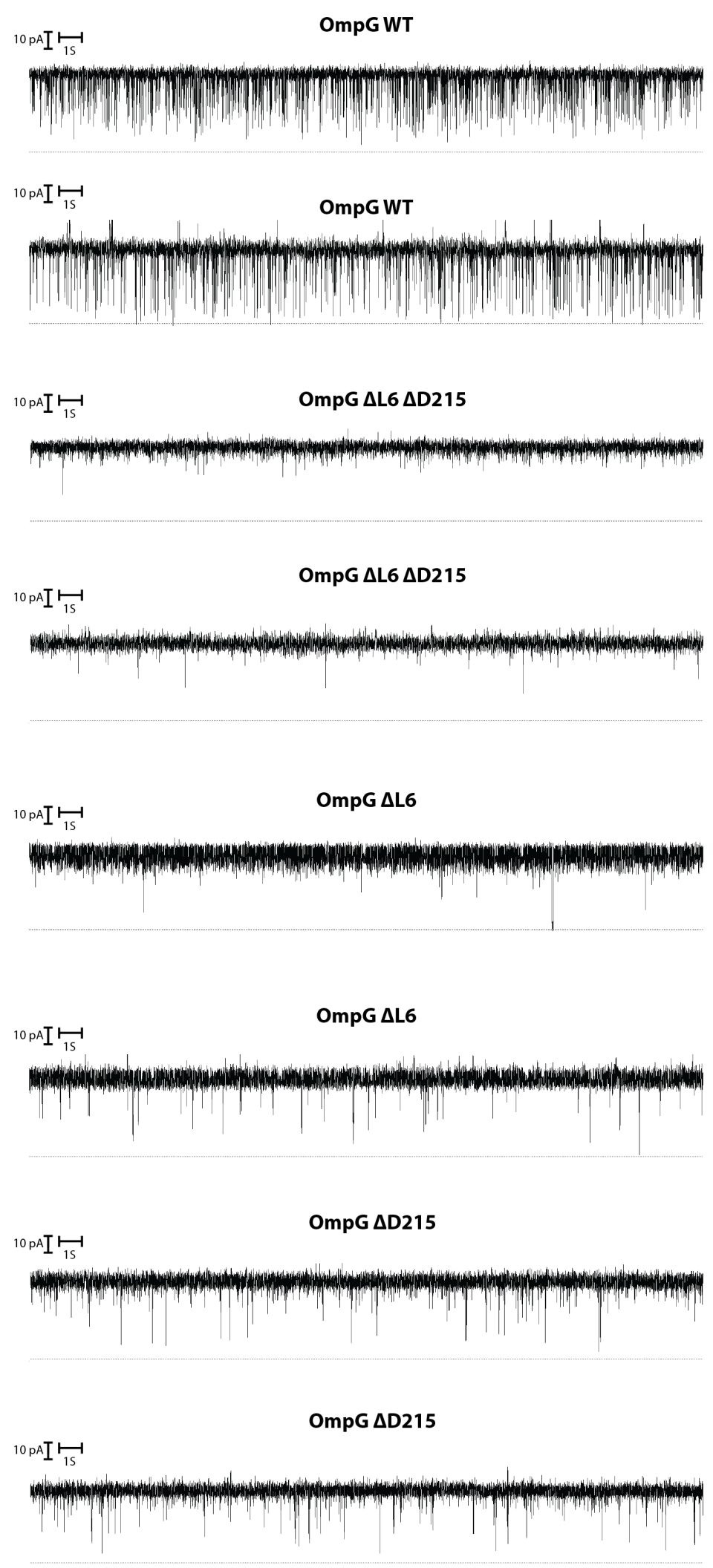

Supplementary Figure S4. Representative longer conductance traces (30s) of wild-type and mutant single OmpG molecules. 


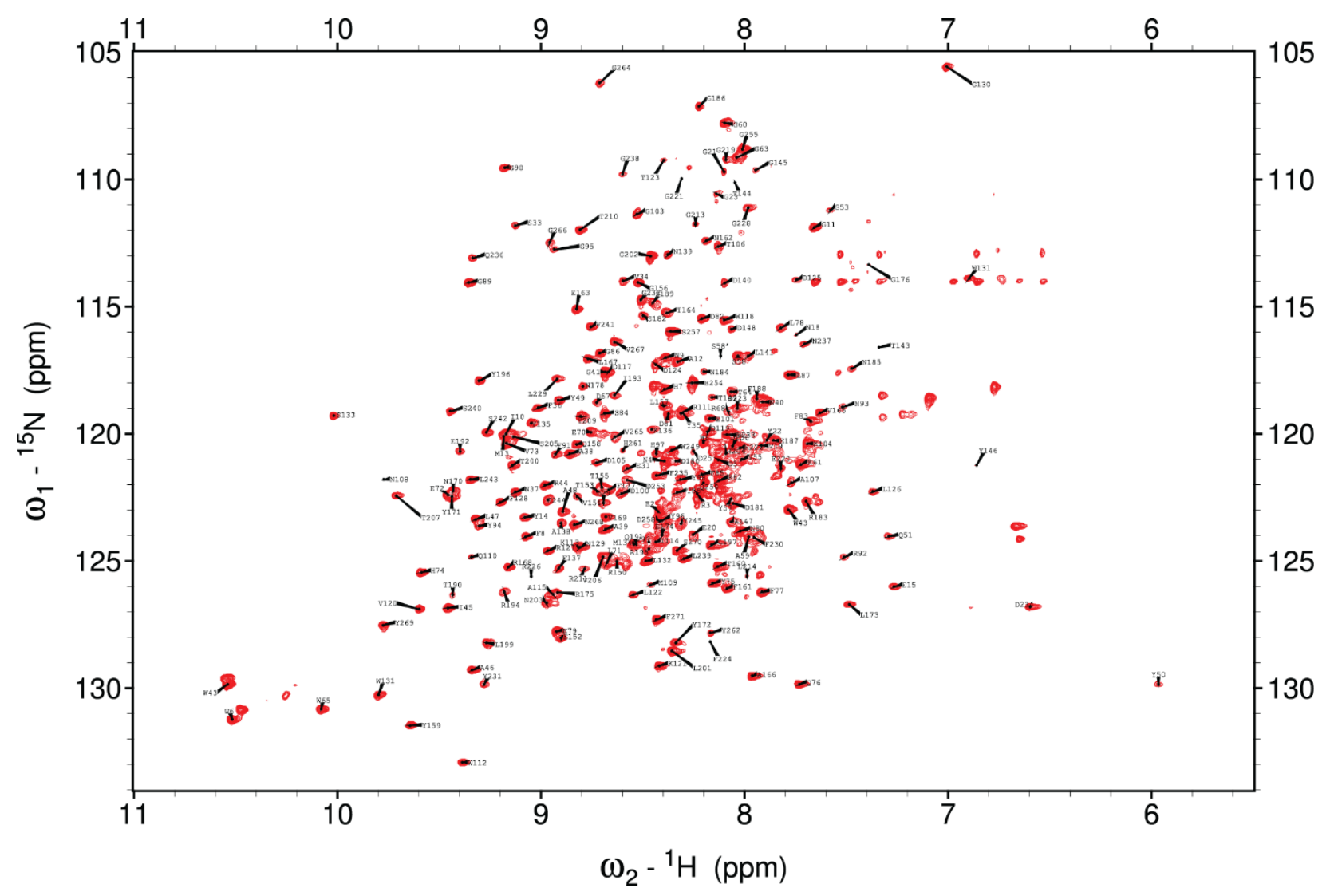

Supplementary Figure S5. ${ }^{15} \mathrm{~N}-{ }^{-} \mathrm{H}$ TROSY-HSQC spectrum of $\triangle \mathrm{L} 6-\Delta \mathrm{D} 215 \mathrm{OmpG}$ in DPC micelles at $\mathrm{pH} 6.3$, collected at $800 \mathrm{MHz}$ proton frequency and $40^{\circ} \mathrm{C}$. Assignments of backbone amides are denoted by one-letter amino acid abbreviations followed by their sequence numbers. 


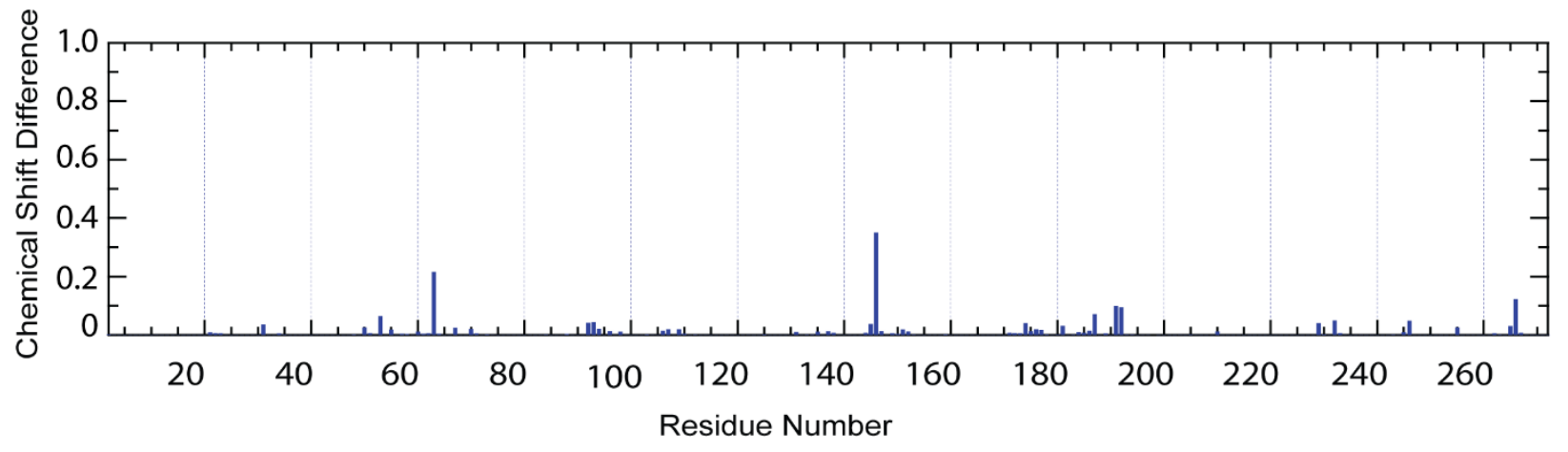

Supplementary Figure S6. Chemical shift changes between $\Delta$ L6 and wild-type OmpG. Chemical shifts were obtained from ${ }^{1} \mathrm{H},{ }_{15} \mathrm{~N}$-TROSY spectra of ${ }^{2} \mathrm{H},{ }_{15} \mathrm{~N}$-labeled protein samples in DPC micelles at pH 6.3 and $800 \mathrm{MHz}$ proton frequency. 

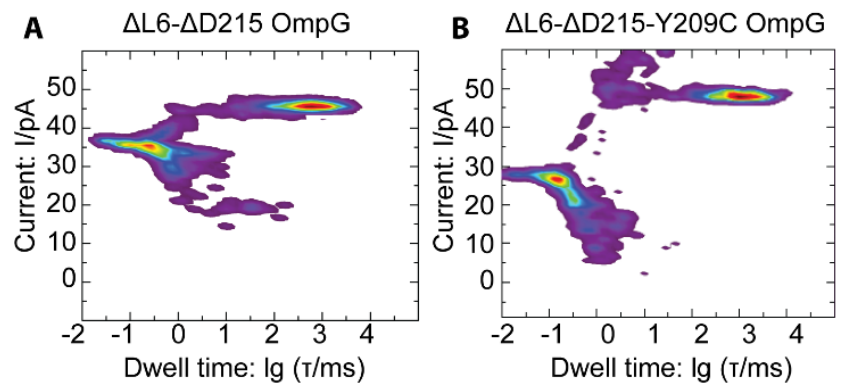

C $\Delta \mathrm{L} 6-\Delta \mathrm{D} 215-\mathrm{Y} 209 \mathrm{CPhen}$ OmpG
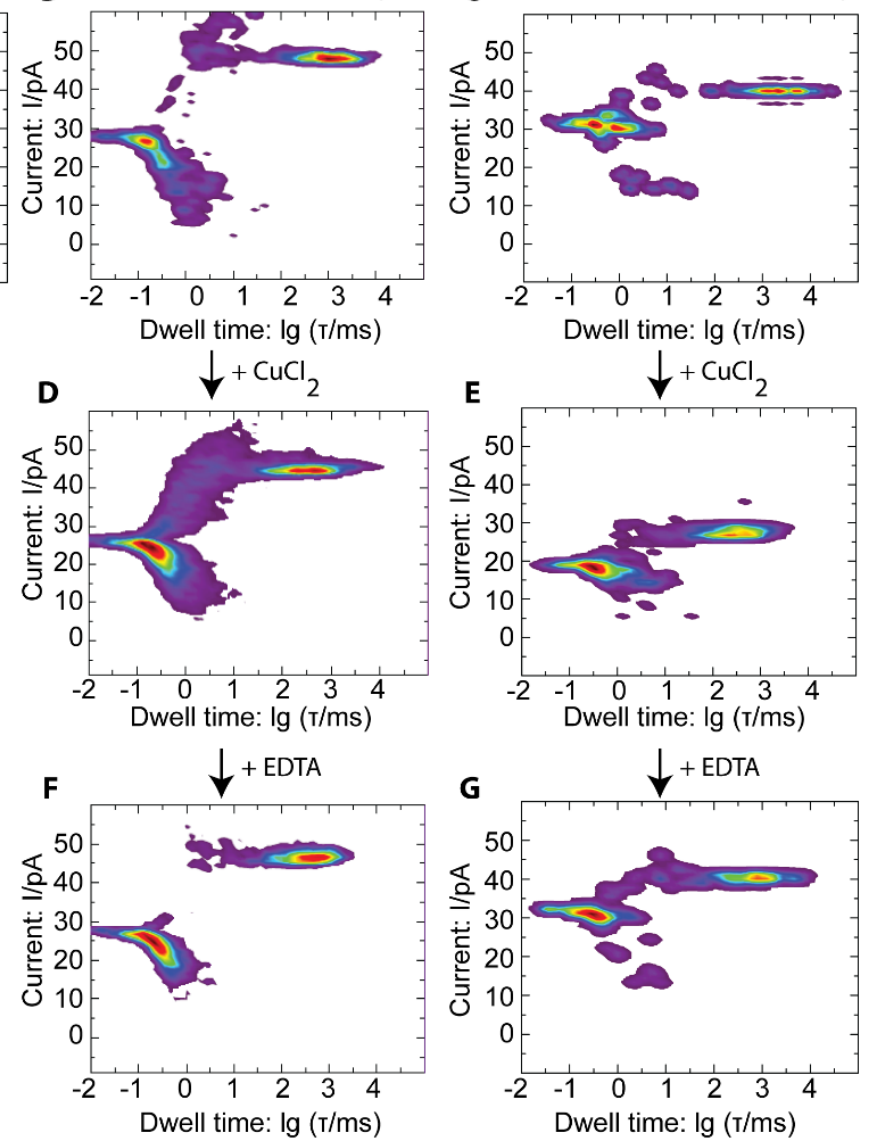

Supplementary Figure S7. Probability density histograms of current versus dwell time distributions for $\Delta$ L6- $\Delta \mathrm{D} 215$ OmpG-based nanopores. A, $\Delta \mathrm{L} 6-\Delta \mathrm{D} 215$ OmpG (reference); B, $\Delta \mathrm{L} 6-\Delta \mathrm{D} 215-\mathrm{Y} 209 \mathrm{C}$ OmpG; and C, $\Delta \mathrm{L} 6-\Delta \mathrm{D} 215-\mathrm{Y} 209 \mathrm{CPhen}$ in the presence of $5 \mu \mathrm{M}$ EDTA (top row), $10 \mu \mathrm{M} \mathrm{CuCl}_{2}$ (middle row, D and E), and excess EDTA $(20 \mu \mathrm{M})$ after $\mathrm{CuCl}_{2}$ addition (bottom row, $\mathrm{F}$ and $\mathrm{G}$ ). 


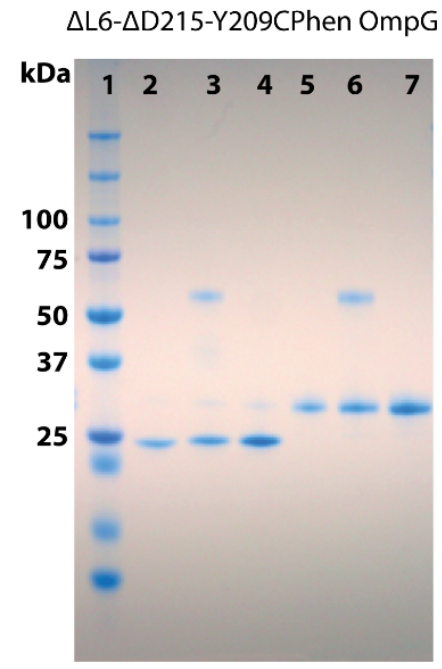

Supplementary Figure S8. Making a biosensor. Refolding of $\Delta$ L6- $\Delta \mathrm{D} 215-\mathrm{Y} 209 \mathrm{CPhen}$ : Lanes 1 to 7 are as follows: Molecular weight markers (1), $\Delta$ L6- $\Delta$ D215-Y209C (2), $\Delta$ L6- $\Delta$ D215-Y209C reacted with phenlA in $8 \mathrm{M}$ urea (3), $\Delta \mathrm{L} 6-\Delta \mathrm{D} 215-\mathrm{Y} 209 \mathrm{C}$ refolded in $\beta$-OG and reacted with phenlA (4). Lanes 5,6 , and 7 are boiled version of lanes 2,3 , and 4 , respectively. 
$\Delta$ L6- $\Delta$ D215-Y209CPhen OmpG + EDTA
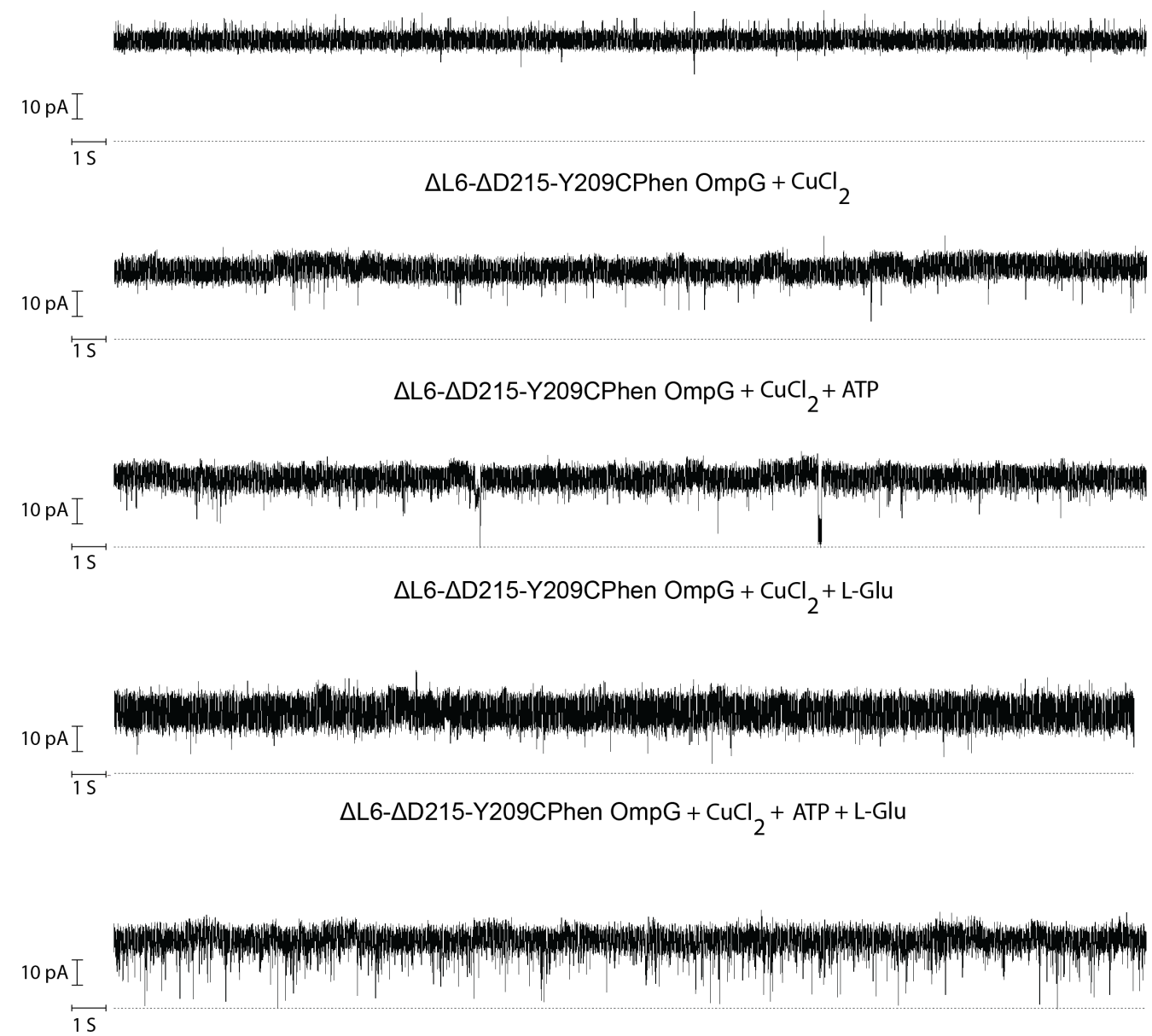

$\Delta$ L6- $\Delta$ D215-Y209CPhen OmpG $+\mathrm{CuCl}_{2}+\mathrm{ATP}+\mathrm{L}-\mathrm{Glu}+\mathrm{EDTA}$

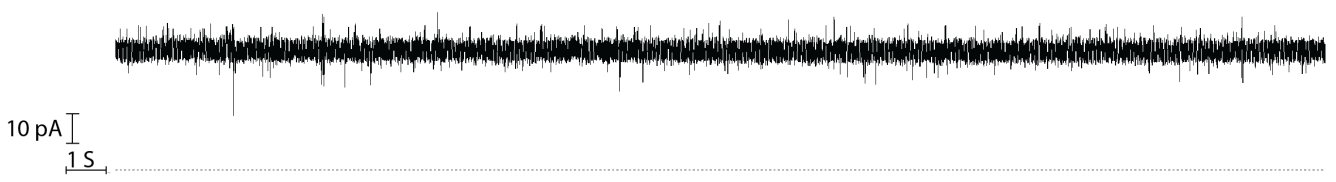

$\Delta \mathrm{L} 6-\Delta \mathrm{D} 215-\mathrm{Y} 209 \mathrm{CPhen} \mathrm{OmpG}+\mathrm{CuCl}_{2}+\mathrm{ATP}+\mathrm{L}-\mathrm{Glu}+\mathrm{EDTA}$

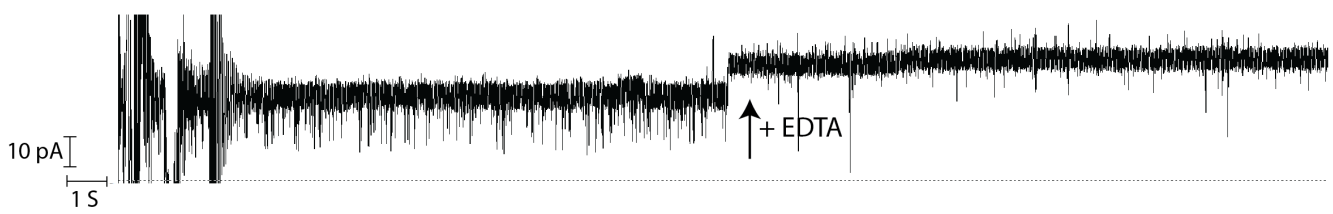

Supplementary Figure S9. Representative longer conductance traces (30s) of $\Delta$ L6- $\Delta$ D215-Y209Cphenanthroline OmpG molecules under various experimental conditions (indicated on top of each trace). Traces are recorded in the presence of $5 \mu \mathrm{M}$ EDTA, $10 \mu \mathrm{M} \mathrm{CuCl}_{2}, 10 \mu \mathrm{M} \mathrm{CuCl}_{2}+20 \mu \mathrm{M}$ of ATP, $10 \mu \mathrm{M} \mathrm{CuCl}_{2}+20 \mu \mathrm{M}$ of L-Glu, $10 \mu \mathrm{M} \mathrm{CuCl}_{2}+20 \mu \mathrm{M} \mathrm{ATP}+20 \mu \mathrm{M} \mathrm{L}-G l u, 10 \mu \mathrm{M} \mathrm{CuCl}_{2}+20$ $\mu \mathrm{M}$ ATP $+20 \mu \mathrm{M} \mathrm{L-Glu}+$ excess EDTA $(20 \mu \mathrm{M})$. 

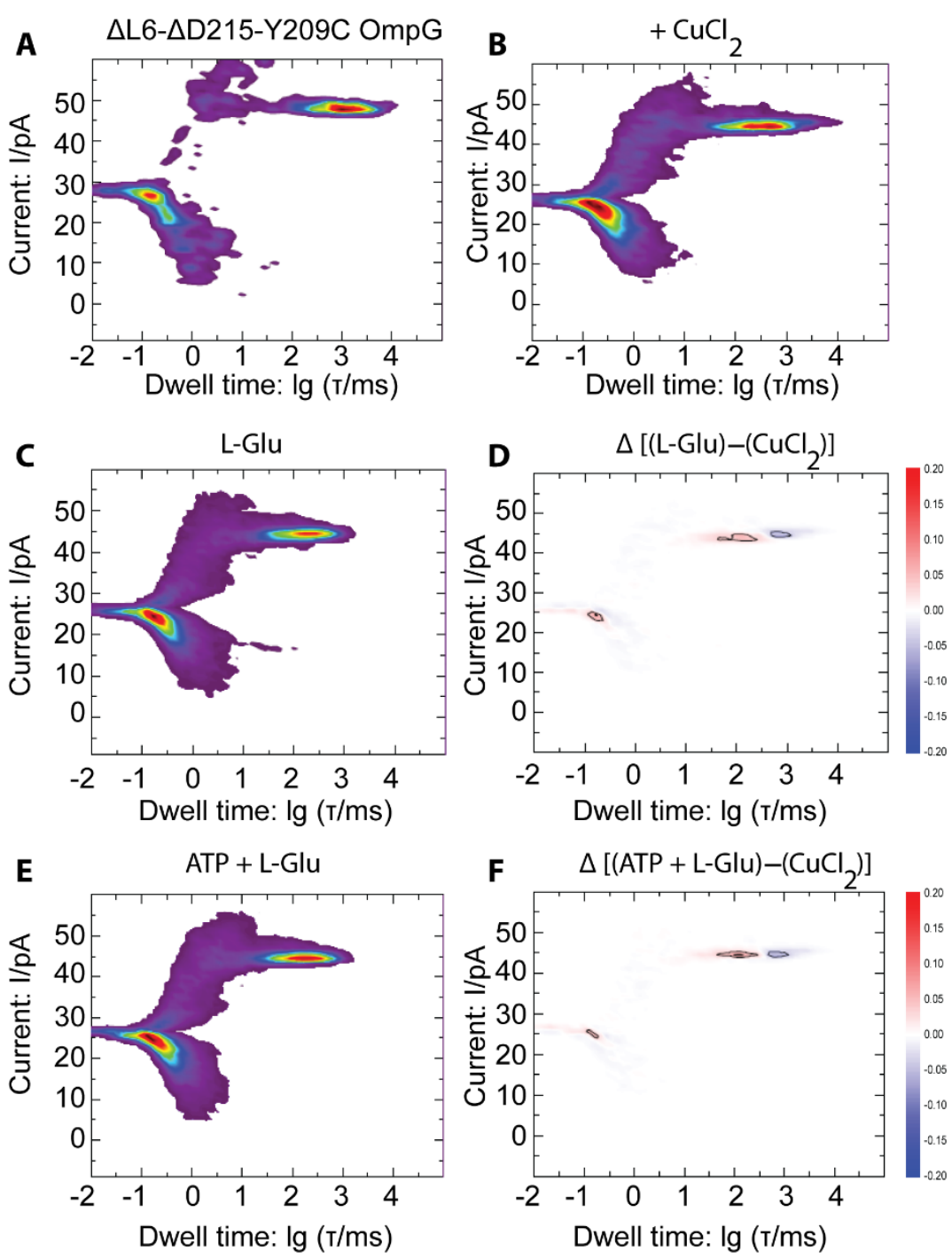

Supplementary Figure S10. Negative controls with single unsensitized (no phenantroline) $\Delta$ L6$\triangle \mathrm{D} 215-\mathrm{Y} 209 \mathrm{C}$ OmpG nanopores. Probability density histograms of current versus dwell time distributions from at least 15 minutes of recordings at $-40 \mathrm{mV}$ in the presence of $5 \mu \mathrm{M}$ EDTA (A), 10 $\mu \mathrm{M} \mathrm{CuCl}_{2}$ alone (B), $10 \mu \mathrm{M} \mathrm{CuCl}_{2}$ and $20 \mu \mathrm{M}$ of L-Glu (C), $10 \mu \mathrm{M} \mathrm{CuCl}_{2}$ and $20 \mu \mathrm{M}$ of analytes ATP and L-Glu (E). Difference maps visualizing the change due to the analytes are shown in D and F. 

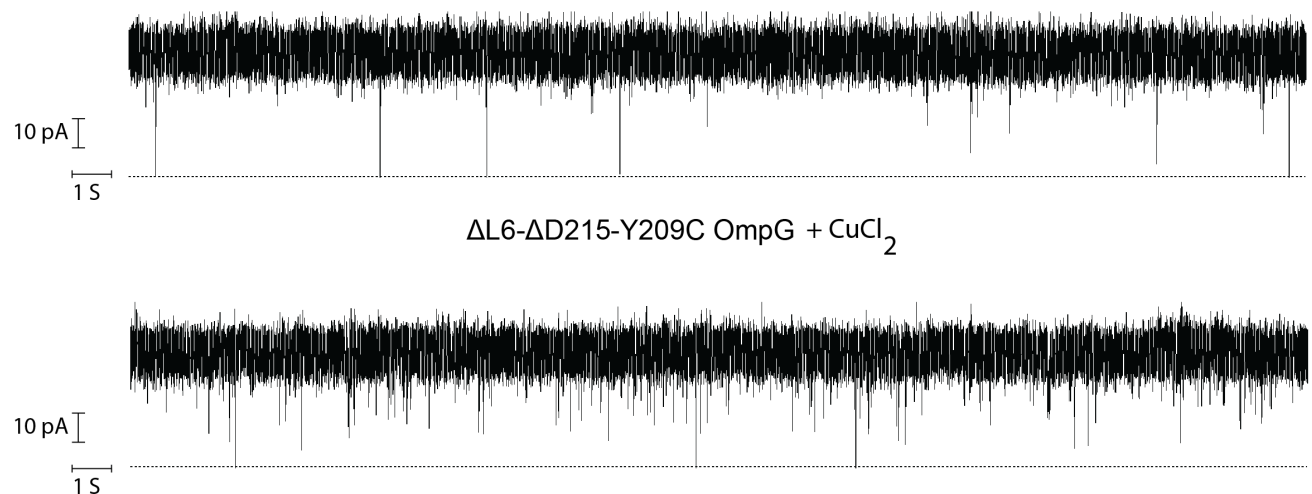

$\Delta \mathrm{L} 6-\Delta \mathrm{D} 215-\mathrm{Y} 209 \mathrm{C} \mathrm{OmpG}+\mathrm{CuCl}_{2}+\mathrm{ATP}$
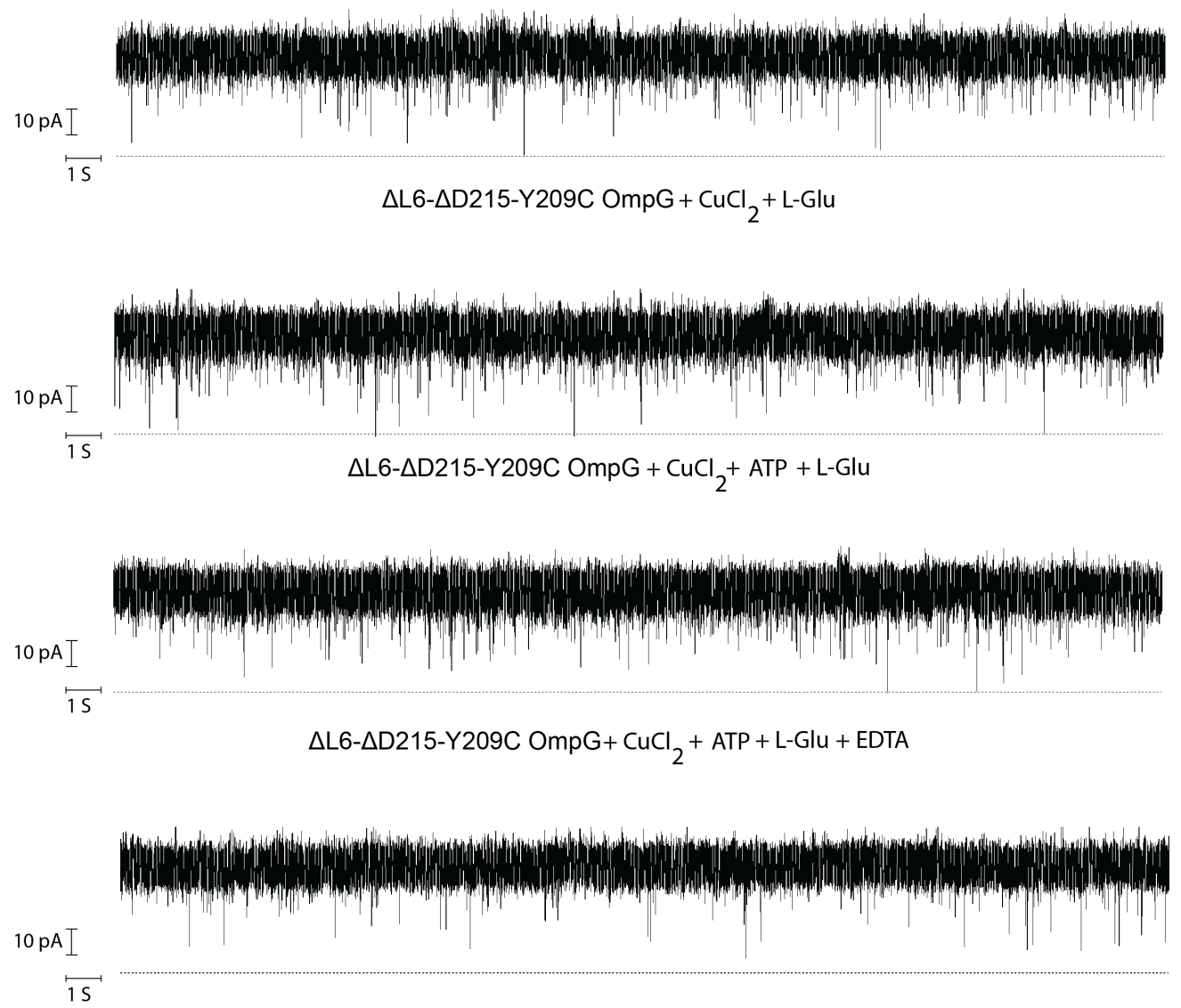

Supplementary Figure S11. Representative longer conductance traces (30s) of negative controls with single unsensitized (no phenantroline) $\Delta \mathrm{L} 6-\Delta \mathrm{D} 215-\mathrm{Y} 209 \mathrm{C}$ OmpG nanopore under various experimental conditions (indicated on top of each trace). Traces are recorded in the presence of $5 \mu \mathrm{M}$ EDTA, $10 \mu \mathrm{M} \mathrm{CuCl}_{2}, 10 \mu \mathrm{M} \mathrm{CuCl}_{2}+20 \mu \mathrm{M}$ of ATP, $10 \mu \mathrm{M} \mathrm{CuCl}_{2}+20 \mu \mathrm{M}$ of L-Glu, $10 \mu \mathrm{M} \mathrm{CuCl}_{2}$ $+20 \mu \mathrm{M} \mathrm{ATP}+20 \mu \mathrm{M} \mathrm{L}-\mathrm{Glu}, 10 \mu \mathrm{M} \mathrm{CuCl}_{2}+20 \mu \mathrm{M}$ ATP $+20 \mu \mathrm{M} \mathrm{L}-\mathrm{Glu}+$ excess EDTA $(20 \mu \mathrm{M})$. 
Supplementary Table 1: Backbone RMSDs of $\beta$-barrel, individual loops, all loops, and combinations of loops of wild-type and $\Delta$ L6_D215 OmpG structures are calculated in MOLMOL. ${ }^{1}$

\begin{tabular}{|l|l|l|}
\hline & WT OmpG $(\AA)$ & $\Delta$ L6_D215 OmpG $(\AA)$ \\
\hline$\beta$-barrel & $1.35 \pm 0.23$ & $1.41 \pm 0.25$ \\
\hline All loops & $9.17 \pm 2.11$ & $7.25 \pm 1.42$ \\
\hline L1 & $3.55 \pm 0.81$ & $3.28 \pm 0.59$ \\
\hline L2 & $2.82 \pm 0.56$ & $2.35 \pm 0.55$ \\
\hline L3 & $1.88 \pm 0.69$ & $2.44 \pm 0.61$ \\
\hline L4 & $1.41 \pm 0.39$ & $2.21 \pm 0.70$ \\
\hline L5 & $2.06 \pm 0.46$ & $2.54 \pm 0.73$ \\
\hline L6 & $4.41 \pm 0.64$ & $3.05 \pm 0.54$ \\
\hline L7 & $3.81 \pm 0.76$ & $3.25 \pm 0.57$ \\
\hline L1-L5 & $5.03 \pm 0.93$ & $6.12 \pm 0.98$ \\
\hline L1-L5, L7 & $6.67 \pm 1.35$ & $7.10 \pm 1.48$ \\
\hline
\end{tabular}

${ }^{1}$ Residues used for these calculations in MOLMOL (Koradi R, Billeter M, Wuthrich K (1996) J Mol Graphics 14:51-55) are 16-32, 51-68, 95-108, 139-149, 176-189, 211-236, and 255-272 for loops 1, $2,3,4,5,6$, and 7 , respectively. For the $\beta$-barrel, the residues are: 7-15, 33-40, 43-50, 69-78, 84-94, 109-121, 126-138, 150-160, 166-175, 190-201, 204-210, 237-243, 248-254, and 273-279. All residue numbering is based on the wild-type sequence. 
Supplementary Table 2: Primers used for mutagenesis. ${ }^{1}$

\begin{tabular}{|c|c|c|}
\hline Number & Name & Sequence $\left(5^{\prime}->3^{\prime}\right)$ \\
\hline 1 & wt-> $-\Delta$ L6I_fw & $\begin{array}{l}\text { GGATCGCTGGAGTAAC/GGTGAAGGCCATGATTTT } \\
\text { AAC }\end{array}$ \\
\hline 2 & wt-> $\Delta$ L6I_rv & $\begin{array}{l}\text { GTTAAAATCATGGCCTTCAC/CGTTACTCCAGCGAT } \\
\text { CC }\end{array}$ \\
\hline 3 & wt $->\Delta \mathrm{D} 215 \_\mathrm{fw}$ & $\begin{array}{l}\text { GTATACGCGCATTGGGCTG/CGCTGGAGTAACTGGG } \\
\text { ACTG }\end{array}$ \\
\hline 4 & wt- $>\Delta$ D215_rv & $\begin{array}{l}\text { CAGTCCCAGTTACTCCAGCG/CAGCCCAATGCGCGT } \\
\text { ATAC }\end{array}$ \\
\hline 5 & $\begin{array}{l}\Delta \mathrm{L} 6 \mathrm{I}->\Delta \mathrm{D} 215 \_\mathrm{f} \\
\mathrm{w}\end{array}$ & $\begin{array}{l}\text { GTATACGCGCATTGGGCTG/CGCTGGAGTAACGGTG } \\
\text { AAG }\end{array}$ \\
\hline 6 & $\begin{array}{l}\Delta \mathrm{L} 6 \mathrm{I}->\Delta \mathrm{D} 215 \_\mathrm{r} \\
\mathrm{v}\end{array}$ & $\begin{array}{l}\text { CTTCACCGTTACTCCAGCG/CAGCCCAATGCGCGTA } \\
\text { TAC }\end{array}$ \\
\hline 7 & Y209C_fw & CTCGGTGACGCCGTGTACGCGCATTG \\
\hline 8 & Y209C_rv & CAATGCGCGTACACGGCGTCACCGAG \\
\hline
\end{tabular}

${ }^{1}$ Base changes and insertions are highlighted in bold. The position of deletions is indicated by a slash '/'. 